\title{
Avian Conservation in the Prairie Pothole Region, Northern Great Plains: Understanding the Links between Climate, Ecosystem Processes, Wetland Management, and Bird Communities
}

\section{Project Scope and Background}

Historically, the Prairie Pothole Region (PPR) of North America was characterized by myriad semi-permanent, seasonal, and temporary wetlands interspersed among rivers in a context of prairie uplands. These wetlands have supported millions of en route and breeding wetland-dependent birds. Today, expanses of the PPR landscape are dominated by intensive agriculture, and many of the remaining habitats have been impacted by altered water regimes, increasing sedimentation, and changes in plant communities. Climate change is likely to cause further alterations by shifting the seasonal availability and distribution of water and vegetation communities. Climate change will also affect the phenology (annual recurrence of phenomena) of vegetation green-up, seed production, and insect emergence. In concert, these changes could alter the capacity of PPR habitats to support waterbirds. Consequently, natural-resource managers and conservation planners in the PPR have an immediate need for effective tools that can evaluate the effects these changes would have on wetland-dependent bird communities.

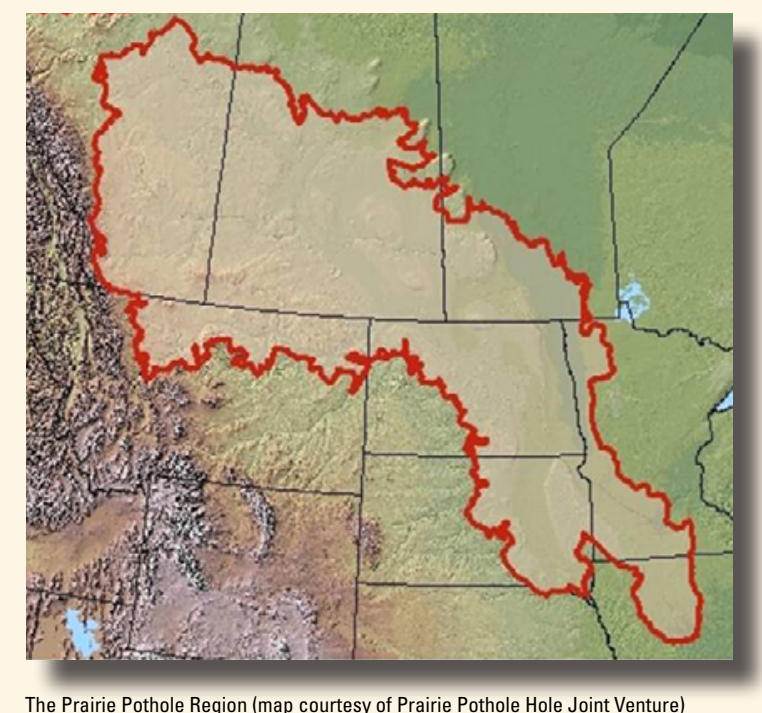

The Prairie Pothole Region (map courtesy of Prairie Pothole Hole Joint Venture)

To that end, a team of U.S. Geological Survey (USGS) scientists and cooperators with expertise in the sciences of climate, hydrology, and ecology has convened to address the potential impacts of climate change on wetland-dependent bird species in the PPR. This team is developing a set of products, including: (1) a synthesis of current knowledge on the interrelationships of climate, wetlands condition, and bird communities; and (2) data on historical and future projections of climate (these projections will be formatted for use in standard mapping software). We will develop models to: (1) forecast effects and biological outcomes of climate change on water quality and quantity in wetlands and riverine ecosystems of the PPR; (2) elucidate relationships between climate, streamflow, water management, and wetland plants; and (3) understand and forecast bird responses to changing habitat conditions and to the timing of resource availability. The outcomes of this research will inform and assist managers and conservation professionals tasked with conserving populations of wetland-dependent birds.

\section{Synthesis: Integrating Our Current Knowledge}

To develop a comprehensive, integrated picture of how wetland processes and biotic communities may respond to changing conditions, we will assimilate and synthesize existing data sets and models, the significant body of knowledge in professional literature, and new findings resulting from our work. Our synthesis will describe: (1) the history of and projected changes in PPR climate, including temperatures and precipitation; (2) geological and hydrological processes that affect PPR wetland and riverine systems; (3) land use and associated changes, including wetland sedimentation and contamination that alter wetland function; and (4) how all these factors might affect wetland habitats and wetland-dependent birds. Our integrative product will include conceptual and empirical models that illustrate the interrelationships among components and processes of wetland and climate changes.

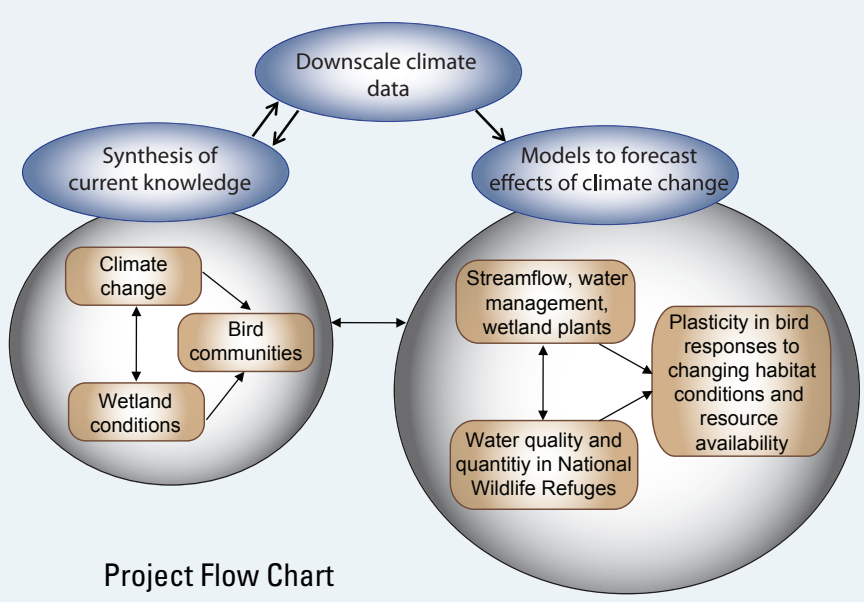




\section{Uncertainty}

Implicit within any attempt to understand socio-ecological systems are many sources of uncertainty which can be categorized as "natural variability" or "knowledge uncertainty". "Natural variability" refers to the inherent randomness observed in nature. In general, it is not possible to reduce the uncertainty within sources of natural variability (for example, probability distributions), but they are important to acknowledge. "Knowledge uncertainty" refers to our inability to perfectly measure and model systems and includes statistical, process, and decision uncertainty. It is possible to reduce knowledge uncertainty through learning and design improvements. Understanding uncertainty is imperative to successfully managing changing socio-ecological systems and provides useful information to decision makers. In assessing the relationships between changing climates and changing ecosystems, we plan to consider a multitude of key uncertainties such as:

- differences in climate-model performance or emphasis,

- variability in ecological and behavioral responses to changing conditions, and

- changes in societal factors such as economics, land-use, or environmental awareness.

\section{Downscaling Climate Data to Regional and Local Scales}

Predictions of future climate are typically based on global atmosphere-ocean general circulation models (AOGCMs), and interpretations of results are meaningful at continental or coarser scales. Naturalresource professionals, however, require much finer-grained projections to develop effective management plans. There are two ways to "downscale" AOGCM data to scales that are fine enough to be applicable to watershed or wildlife refuges: (1) statistical downscaling, which is based on the relationship of large-scale AOGCM data to weather-station observations, and (2) dynamical downscaling, which is based on the physics of how the atmosphere behaves. Statistical approaches become problematic when future temperature means and ranges extend beyond the range of historical values. Given the potential for future

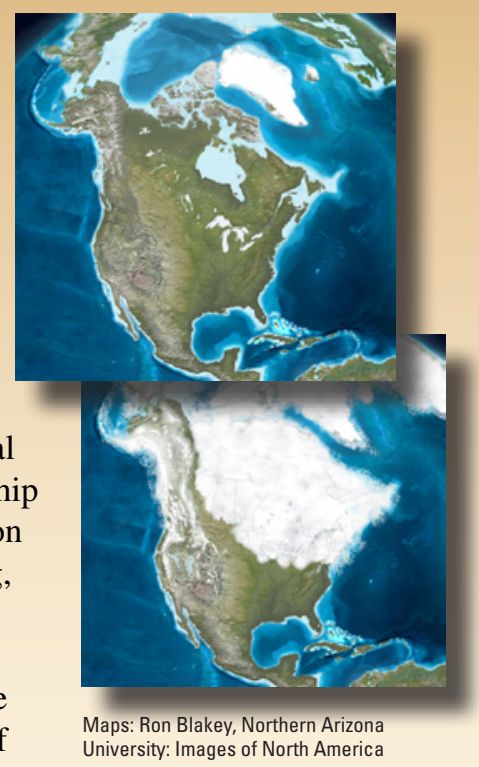
climate to behave in ways not seen in historical times, the USGS-sponsored project will use the Weather Research and Forecast (WRF) Model, which is a dynamical model used by several weather agencies, including the University Corporation for Atmospheric Research. Members of our team have set up the WRF model on a supercomputer at the University of Colorado at Boulder (the Community Surface Dynamics Modeling System, or CSDMS) to downscale data for simulating historical (1975-2010) and projecting future (2010-2080) climate conditions across the PPR. The end-product models of this work will be available to natural-resource professionals for simulating scenarios of future natural-resource conditions.

\section{Linkages between Wetland Ecology and Climate Change}

\section{Riverine wetlands}

Many wetlands in the northern Great Plains are hydrologically connected to riverine systems of the Missouri River Basin, where trends in precipitation and streamflow show a pattern of decreasing to increasing along a northwest-to-southeast gradient. These trends will lead to changes in water availability that may diminish habitat quality and quantity for migratory wetland- and riparian-dependent birds. To quantify the degree to which wetlands and riverine ecosystems are sensitive to the effects of climate change, we are integrating climate models with streamflow and weather data from the Missouri River Basin to develop hydroclimatic models. These models will allow us to estimate changes in hydroperiod, water depth, water quality (that is, salinity), and water temperature for various climate-change scenarios. Because organisms vary in their tolerances to soil and water salinity, habitat suitability for plants, invertebrates, and birds may be altered by changes in wetland salinity. We will focus on three National Wildlife Refuges (Bowdoin NWR, Long Lake NWR, and Sand Lake NWR) that represent a dry-towet gradient to determine how climate-driven changes in water quantity and temporal availability may impact wetland habitats and water management. We also will analyze tree rings of cottonwood and juniper along the Little Missouri River to reconstruct precipitation and flow over the past 300 years and combine this information with downscaled climate projections to predict changes in cottonwood establishment and growth resulting from human-induced climate change.

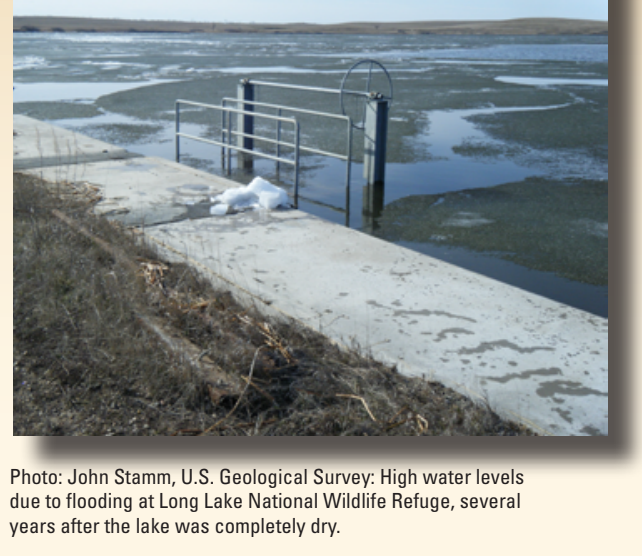




\section{Linkages between Wetland Ecology and Climate Change}

\section{Palustrine wetlands}

Migratory and breeding birds use palustrine (temporary, seasonal, and semi-permanent) wetlands within the PPR, but drainage, intensive agriculture, and other human activities have significantly altered these isolated wetlands. This has potentially diminished their habitat value to the birds dependent on them. Climate change and land-use practices may compound these effects by shifting when and to what extent the palustrine wetlands fill with water. To elucidate how these changes will affect wetlands in the PPR at critical times in birds' annual cycles, we will develop models that relate historical survey data on wetland conditions to climate, land use, landscape configuration, and water-management activities. In addition, we will refine a spatially explicit model to forecast effects of changing climate and agricultural practices on rates of sedimentation of prairie wetlands. Collectively, this information will help wildlife managers prepare strategies for mitigating climate-driven changes in palustrine habitat conditions.

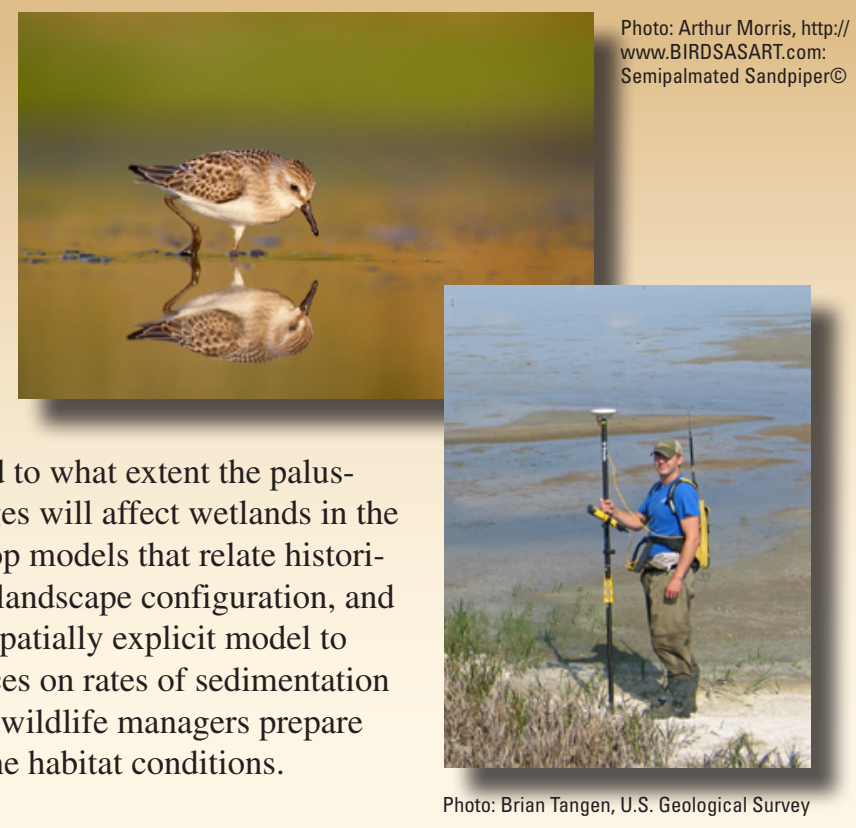

\section{Responses of Wetland-Dependent Migratory Birds to Changing Wetland Conditions}

For most species of waterbirds that migrate through or breed in the PPR, habitat and food resources are directly related to the distribution and condition of wetlands across the landscape. The USGS-sponsored project will focus on five families of birds: Anatidae (ducks and geese), Ardeidae (herons), Scolopacidae (sandpipers), Laridae (gulls and terns), and Emberizidae (especially warblers associ-

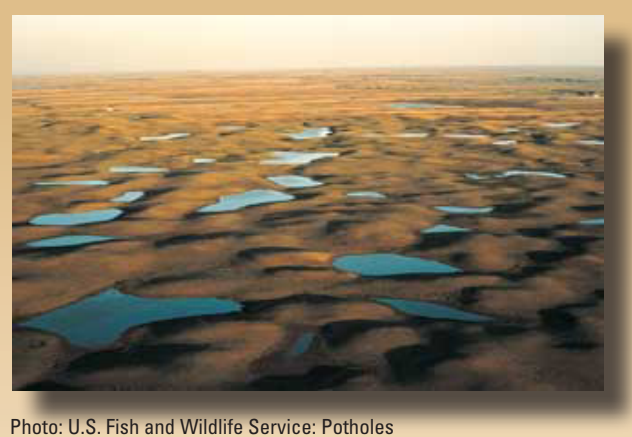
ated with riparian forests). At the broadest scale, the project will use existing survey data and newly gathered field data to model the distribution of several breeding and migrating wetland-dependent bird species relative to landscape attributes and past climate. Project scientists will then use climate projections and wetland-condition models to evaluate species' vulnerability to habitat loss given various simulated scenarios of ecosystem change. Project scientists also will summarize what is known about waterbird behavioral flexibility in habitat use and the abilities of waterbirds to track climate-driven changes in habitat and food resources.

Overall, components of the PPR-wide modeling work will give managers and conservation planners a picture of how waterbird habitats across the PPR landscape may change so that they may plan how to best mitigate the effects of climate change. Additionally, we will conduct field studies of the

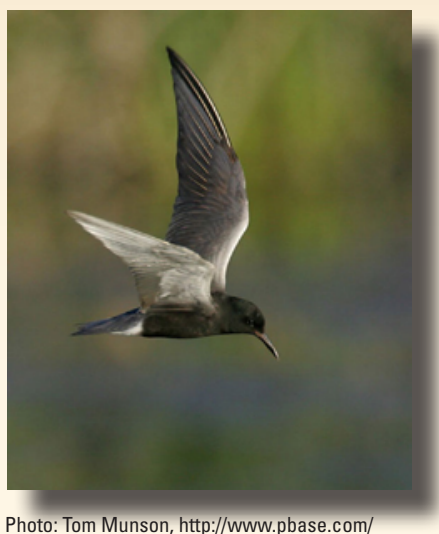
clinton62/root: Black Tern® relations between shorebirds and their habitat during migration and the sensitivity of shorebirds to changes in the timing of insect and plant emergence that often characterizes climate change. Specifically, we will measure how birds respond to variations in food availability across an elevational gradient within a context of seven alternative land-use types. This will allow us to simultaneously assess the relative importance and synergistic interactions of climate and land-use on migrating bird populations. The results of this work will equip resource professionals with information which will allow them to develop a range of adaptive management approaches that can take into account the high degree of uncertainty associated with natural variations in climate, bird behaviors, models, and changes driven by human activities. 


\section{Project Principal Investigators and Cooperators}

\section{Bird Component}

Susan K. Skagen, U.S. Geological Survey, Fort Collins Science Center Joseph J. Fontaine, U.S. Geological Survey, Nebraska Cooperative Fish and Wildlife Research Unit Ryan Stutzman, Nebraska Cooperative Fish and Wildlife Research Unit Valerie Steen, U.S. Geological Survey, Fort Collins Science Center Cynthia P. Melcher, U.S. Geological Survey, Fort Collins Science Center

\section{Climate Component}

John Stamm, U.S. Geological Survey, South Dakota Water Science Center Gary Clow, U.S. Geological Survey, Cryospheric Studies, Denver Federal Center Mark Anderson, U.S. Geological Survey, South Dakota Water Science Center Parker Norton, U.S. Geological Survey, South Dakota Water Science Center

\section{Wetland Component}

Neal Niemuth, U.S. Fish and Wildlife Service, Habitat and Population Evaluation Team Jonathan M. Friedman, U.S. Geological Survey, Fort Collins Science Center Robert Gleason, U.S. Geological Survey, Northern Prairie Wildlife Research Center Brian Tangen, U.S. Geological Survey, Northern Prairie Wildlife Research Center Diane Granfors, U.S. Fish and Wildlife Service, Habitat and Population Evaluation Team Lucy Burris, Colorado State University

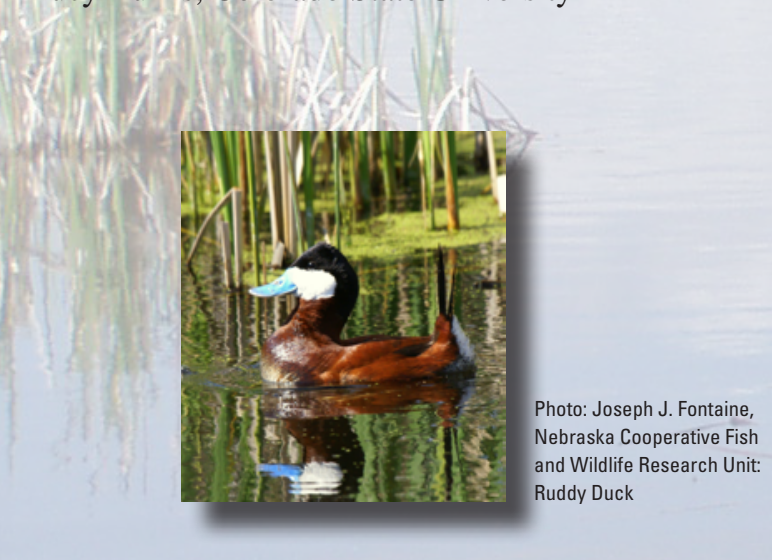

Funding and In-Kind Support Provided by:
Photo: David Chauvin: Soraㄷ
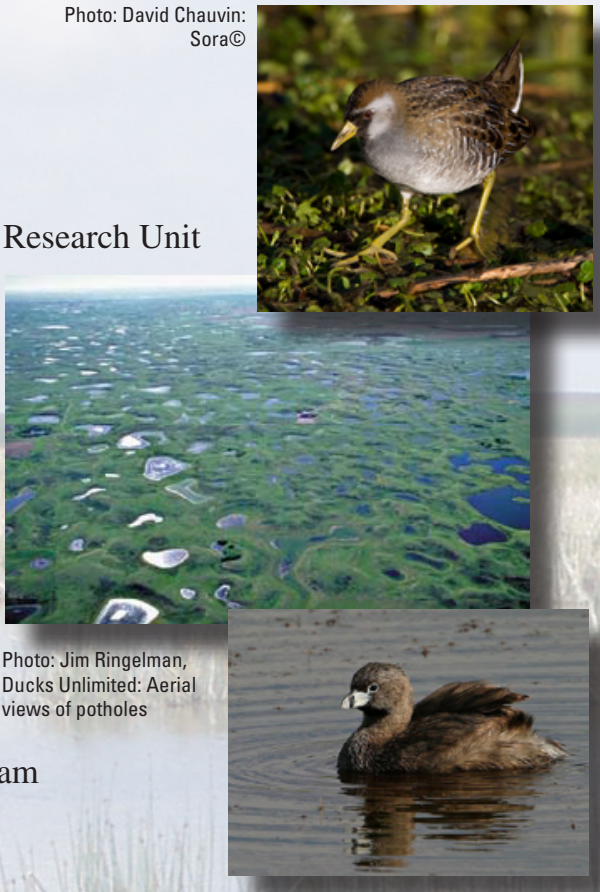

Photo: Tom Munson, http://www.pbase.com clinton62/root: Pied-billed Grebe®

\section{Plains and Prarie Potho Land ape Conservatien Cooperative, Prisie Pohole Join Vente}

Plains and Prairie Pothole Landscape Conservation Cooperative, Prairie Pothole Joint Venture

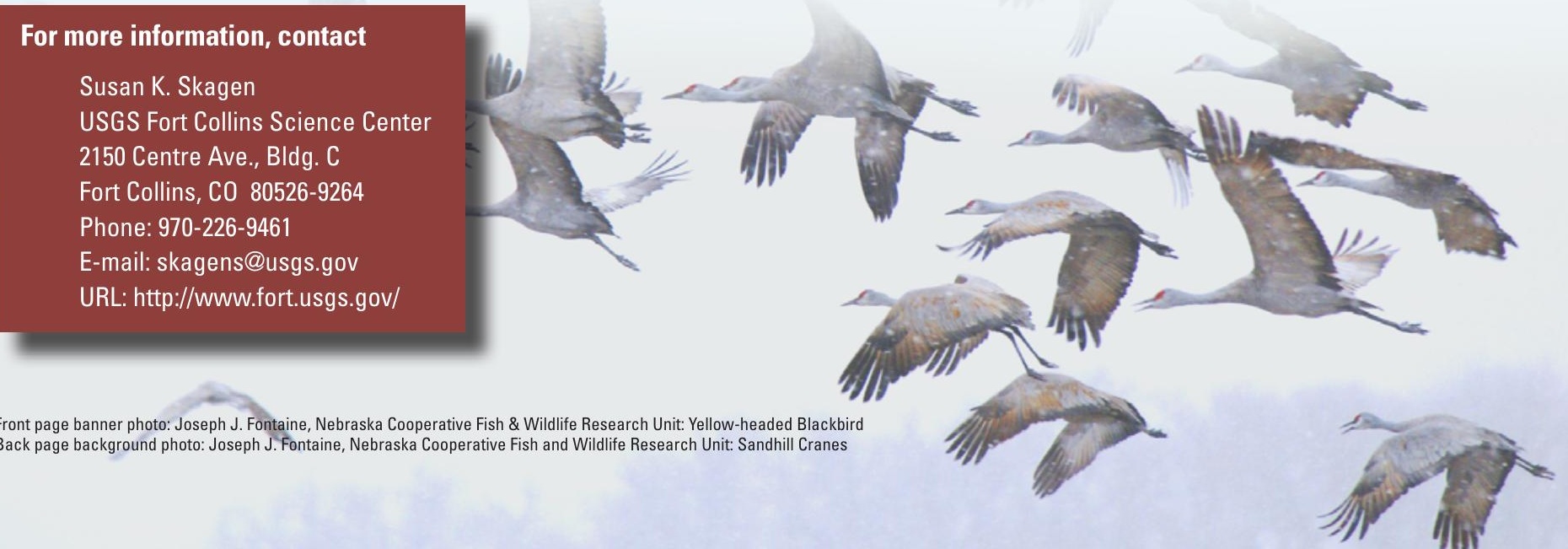

